\title{
Morphological and molecular-based identification of Aedes aegypti (Diptera: Culicidae), a main vector of Dengue Fever, the first record in Iran after decades.
}

\section{Hedayat Dorzaban}

Department of Medical Entomology and Vector Control, School of Health, Shiraz University of Medical Entomology, Shiraz, Iran.

\section{Aboozar Soltani}

Research Center for Health Sciences, Institute of Health; Department of Medical Entomology and Vector Control, School of Health, Shiraz University of Medical Sciences, Shiraz, Iran.

\section{Hamzeh Alipour}

Research Center for Health Sciences, Institute of Health; Department of Medical Entomology and Vector Control, School of Health, Shiraz University of Medical Sciences, Shiraz, Iran.

\section{Jafar Hatami}

Tehran University of Medical Sciences

\section{Seyed Aghil Jaber Hashemi}

Department of Medical Entomology and Vector Control, School of Health, Shiraz University of Medical Entomology, Shiraz, Iran.

\section{Marzie Shahriari-Namadi}

Department of Medical Entomology and Vector Control, School of Health, Shiraz University of Medical Sciences, Shiraz, Iran.

\section{Reza Safari}

Infectious and Tropical Diseases Research Center, Hormozgan Health Institute, Hormozgan University of Medical Sciences, Bandar Abbas, Iran.

Kourosh Azizi ( $\square$ azizik@sums.ac.ir)

Shiraz University of Medical Sciences

\section{Research}

Keywords: Aedes aegypti, Dengue Fever, vector surveillance, C01 Gene, Iran

Posted Date: April 6th, 2020

DOl: https://doi.org/10.21203/rs.3.rs-20236/v1 
License: (c) (i) This work is licensed under a Creative Commons Attribution 4.0 International License. Read Full License 


\section{Abstract}

Background : Aedes aegypti is an important vector for transmission of some dangerous arboviral diseases including Dengue Fever. This study was conducted for the first time in Iran in order to survey the existence of this invasive species in oriental parts of the country located near the Persian Gulf during August 2017 to January 2020.

Methods : Different sampling methods were used to collect all stages of mosquitoes in five selected cities of Hormozgan province, south of Iran. After morphological identification, a molecular study based on Cytochrome Oxidase (CO1) gene-specific primers was performed to identify them more precisely. Then, the $\mathrm{CO} 1$ gene were sequenced via the Sanger method.

Results : Totally, 4560 adults and 3520 larvae were collected from all sampling areas. Thirty-one Aedes aegypti specimens were identified from Bandar Khamir and Bandar Lengeh seaports.

Conclusion : Based on the biology and ecology of Aedes aegypti, the possibility of establishment of this species in this region is very high due to the tropical climate of this region. Considering the detection of this invasive vector, high incidence of some arboviral diseases in the neighboring countries, and continuous movements of the settlers of these areas, some potential outbreaks of arboviral diseases can be predicted. Thus, planning and implementing an immediate preventative and surveillance program is vital in order to prevent the establishment of this invasive vector in this area.

Keywords : Aedes aegypti , Dengue Fever, vector surveillance, C01 Gene, Iran

\section{Background}

Mosquito-borne diseases are among the most serious public health problems in the world. The correct diagnosis of vectors is one of the most important factors in identifying the transmission of vector-borne diseases $[1,2]$. Before molecular methods were introduced for the classification and identification of mosquitoes, they were identified and categorized based on their morphological characteristics. Owing to the recent advancements in technology, performing cytogenetic analyses and detecting Cytochrome Oxidase (CO1) enzyme indices have become quite feasible [3]. The molecular method can be very useful for identifying mosquitoes, because the samples that are not detectable and well maintained through morphological assay can be easily identified by this method [4]. Molecular method can be employed for the identification of sibling species as well as those that are morphologically similar to a certain population [5]. Up to now, several specific molecular markers with a high level of accuracy, such as Internal Transcribed Spacers (ITSs) of ribosomal DNA genes, 28S rDNA gene, mitochondrial Cytochrome Oxidase C subunit I and II (COI \& COII), and Cytochrome Oxidase B, have been employed for the detection of species [4, 6-7].

Mosquito-borne diseases represent one of the most important public health issues all over the world. One of the most dangerous species that can be the vector of some serious and deadly arboviral diseases is 
Aedes aegypti [8]. Aedes aegypti lives in tropical and subtropical areas next to human habitats. Aedes aegypti eggs are very resistant to drought, and the mosquitoes usually lay them on the wet inner walls of containers with water or above the waterline. The eggs hatch into larvae within two days at a temperature of $27-30^{\circ} \mathrm{C}$. The larvae turn into pupae after eight days. The larvae of this species are found in humanmade containers, such as pottery jugs, water storage tanks, drink cans, empty pots, broken bottles, and old tires, which are all used for keeping water inside and outside farm buildings located 500 meters away from residential areas. The larvae can also be easily found in tree holes, branches, bamboo trees, and even coconut trees. Larvae usually spend long periods of time underwater in deep-water areas to find food.

Female mosquitoes usually suck blood in the shade during daytime and sometimes enter low-light places at nights. Aedes aegypti are highly anthropophilic, such a way that each blood intake occurs with 2-4-day intervals. After the blood-sucking process, the resting phase usually takes place in indoor areas, such as cabinets or behind doors. Adult mosquitoes do not normally fly over long distances and usually spread up to a few hundred meters from their larval breeding places. The main origin of this species was in Africa, which was then gradually spread to other tropical areas.

Ae. aegypti is one of the species that can easily establish in a new region and adapt itself to the new conditions. So far, numerous studies have been conducted on the biological and medical importance of this invasive species in the world [9-12]. Many molecular studies have also been carried out to identify mosquito vectors in Iran. The majority of these studies have been focused on malaria vectors, while limited studies are available regarding Aedes mosquito. In fact, no comprehensive research has been carried out on Aedes mosquito with a focus on Ae. aegypti in Iran. There are some nonofficial reports of Ae. aegypti in southern parts of Iran a few decades ago as the same species or other species such as Ae. argenteus or Stegmyia fassiata [13] but there is no samples $r$ reliable documentary of intent. Considering the reporting of some important arboviral diseases such as yellow fever, chikungunya, and dengue fever and their vectors in neighboring countries, the present study was conducted for the first time in Iran in order to survey this species in Hormozgan province (an oriental region located in the southern part of Iran near the Persian Gulf) during August 2017 to January 2020.

\section{Methods}

\section{Study area}

Hormozgan province with an area of 68,379 square kilometers $\left(27.1387^{\circ} \mathrm{N}, 55.1376^{\circ} \mathrm{E}\right.$, altitude $\left.9.14 \mathrm{~m}\right)$ is located in southern Iran. Hormozgan province borders the Oman Sea and the Persian Gulf, stretching about 10,000 km along the coastline. This province has 12 small and large islands as well as 13 cities, namely Bandar Abbas, Bandar Lengeh, Minab, Rudan, Bandar Khamir, Jask, Parsian, Bastak, Hajiabad, Qeshm, Abu Musa, Bashagard, and Cirik (Fig. 1). The weather is hot and humid. The province receives very little rainfall in most areas, with an average annual precipitation of $150-200 \mathrm{~mm}$. Kishi is one of the villages of the seaport city of Bandar Khamir. This village is located in a valley and has many palm trees, 
seasonal streams running through the village, and several seasonal rivers. These conditions are favorable for the growth and development of mosquitoes. Bandar Lengeh is also a seaport of great economic and commercial importance in Hormozgan province with geographical coordinates of $26^{\circ} 54^{\prime} 60.49^{\prime \prime} \mathrm{N}$, 5487'96.63"E (Fig. 1).

\section{Sampling methods}

From the beginning of 2017, all stages of Aedes mosquitoes were collected from five selected regions across Hormozgan province (Bandar Abbas, Bandar Lengeh, Bandar Khamir, Jask, and Bashagard). The mosquitoes were caught by different techniques, including total catches (pyrethrum spray catch), hand catch, pit shelters, and light traps, for collecting adults. Larval stages and eggs were collected by WHO dipping method as well as by ovitraps installation. The potential breeding sites that were inspected for Aedes mosquitos were water reservoirs, pots, bottles, drinking water springs, small and large pools, jars, discarded tires, cisterns, and installed ovitraps (Figs. 2 and 3).

\section{Morphological identification}

All collected adults and larvae were identified morphologically using valid pictorial keys [9, 14-15]. The specimens that were suspected of Aedes aegypti were selected for further molecular studies to confirm the sample identification.

\section{Molecular identification}

\section{DNA extraction}

DNA molecules were extracted from the whole body of mosquitoes using a DNA extraction kit (Sinaclon, Iran). Then, the extracted DNA molecules were treated with RNasel (Roche Germany) according to the manufacturer's instructions and were stored at $-20^{\circ} \mathrm{C}$.

\section{Primer design}

The nucleotide acid sequence of the $\mathrm{CO} 1$ Ae.aegypti gene, which had already been deposited and recorded in the Gene Bank (NCBI) by other researchers was used as the primer design for identifying Aedes aegypti species. The following four Aedes aegypti $\mathrm{CO} 1$ nucleic acid sequences were extracted from NCBI: MN019006.1, LC482636.1, LC482632.1, and LC482631.1. The sequences were aligned by MEGA 6.0 software. Then, the primers were designed based on the conserved points. DNA alignment was done by MEGA6 software based on ClustalW. In addition, a pair of primers was designed based on the conserved points using Oligo.7 software, with an expected size band of about 370 base pairs (Table 1). The primers were synthesized by the Bioneer Company (Republic of Korea). 
Table 1

The primers designed and used to identify Aedes aegypti mosquitoes

\begin{tabular}{|c|c|c|c|}
\hline & Primers & Sequences & Expected size \\
\hline 1 & Fage & 5'-AACAGTTTATCCTCCTCTCTCTTCAG-3' & \multirow[t]{2}{*}{$370 \mathrm{bp}$} \\
\hline 2 & Rage & 5囚-AATCCGGGTAAAATTAAAATATAAACTTCTGG-3' & \\
\hline
\end{tabular}

All Polymerase Chain Reactions (PCRs) were performed in a total volume of $20 \mu \mathrm{l}$ for 35 cycles, using $100-200 \mathrm{ng}$ of genomic DNA in each reaction as templates. The reaction mixture contained $400 \mathrm{nM}$ of each primer, $1.5 \mathrm{mM}$ of $\mathrm{MgCl} 2,1$ unit of Taq DNA polymerase, $0.2 \mathrm{mM}$ of dNTPs, and $2 \mu \mathrm{l}$ of $10 \mathrm{X}$ reaction buffer, with the final volume being adjusted to $20 \mu \mathrm{l}$ with Double Distilled Water (DDW). The amplification program was set as follows: 5 min at $94^{\circ} \mathrm{C}$ followed by 35 cycles of denaturation at $94{ }^{\circ} \mathrm{C}$ for $30 \mathrm{~s}$, annealing at $58{ }^{\circ} \mathrm{C}$ for $30 \mathrm{~s}$, extension at $72{ }^{\circ} \mathrm{C}$ for $80 \mathrm{~s}$, and an additional final extension at $72{ }^{\circ} \mathrm{C}$ for $10 \mathrm{~min}$. The amplified amplicons were purified using the DNA gel purification kit (GF-1 Vivantis, Malaysia). In order to confirm the expected size band, PCR assay was sequenced by the primers introduced by Pishgam Biotech Company, Iran.

\section{Sequencing}

The expected size bands after gel purification were sequenced and subsequently analyzed and assembled via Chromas (version 2.31, 2005), DNA star (version 7.10, 2006), and BLAST by NCBI online. The amplicons with sizes close to the predicted range were sequenced using forward and reverse Gene Specific Primers (GSPS) in two sequencing readings.

\section{Results}

Entomological checks were conducted in Hormozgan province on a monthly basis from August 2017 to January 2020. The entomological survey was done across 60 villages in five selected cities. A total of 2500 houses were surveyed for the presence of Aedes aegypti. In this study, 4560 adults and 3520 larvae of mosquitoes were collected and identified morphologically. After the morphological identification of all specimens, 31 samples (three adults from Kishi village in Bandar Khamir and 25 larvae and three adults from Bandar Lengeh) were identified as Aedes aegypti. A part of these specimens was selected for molecular confirmation.

All three collected adult mosquitoes in Bandar Khamir (Kishi village) were captured in a sheep stable in March 2017. Kishi had an average temperature of $32{ }^{\circ} \mathrm{C}$ in March, with the lowest temperature being $12{ }^{\circ} \mathrm{C}$ during the same period. Moreover, the lowest and highest levels of relative humidity were $32 \%$ and $72 \%$, respectively. Besides, the average rainfall was $6.2 \mathrm{~mm}$ throughout the mentioned time period. In this region, Aedes aegypti was collected only in March. Although all old tires and other artificial breeding places around the houses were checked weekly, no larvae of Aedes aegypti was detected in this area. 
Larvae and adults of Ae. aegypti were also collected in Bandar Lengeh (around a carting track that was full of scrap tires) by dipping and hand catch methods, respectively in December 2019.

Females of Aedes aegypti mosquitoes have a moderate size, with a pattern of scales on the head, chest, legs, and abdomen. This species can be easily distinguished from other members of the genus due to the white lyre shape on the dorsal side of the thorax $[9,14]$. All major morphological characteristics of this species have been shown in Figs. 4 and 5 .

The whole body of mosquitoes, or a part of the body, can be useful for molecular studies [16]. Using the PCR assay and gene replication of the COI portion $370 \mathrm{bp}$ for Ae. Aegypti, it was found that this method was useful in providing a reliable source of the DNA genome in the molecular identification of mosquitoes. In this study, the band was implied by conventional PCR assay and the expected size was 370 bp (Fig. 6).

The tested specimens were identified as Ae. aegypti (Fig. 7). The amplified partial COI sequence of Ae. eagypti characterized in this research was submitted to the Gene Bank (Gene Bank accession no. MT122745). The DNA of Aedes eagypti COI sequence was aligned by Nucleotide BLAST. The sequence showed $100 \%$ similarity to Aedes aegypti mitochondrial subunit 1 sequence (MN019006).

A phylogenetic tree of $\mathrm{COI}$ was constructed on the basis of the $\mathrm{COI}$ nucleic acid sequence of different mosquitoes by using the maximum likelihood method. The results of phylogenetic analysis showed that the most similar physiological function and evolutionary relatedness were associated with Aedes eagypti subunit 1 (Fig. 8)

\section{Discussion}

In the present study, larvae and adults of Aedes agypti were collected from two different parts of the oriental area of Iran for the first time. Surprisingly, all Aedes agypti mosquitoes were collected from the coastal areas of the province. This crucial point reinforced the theory that this invasive species has entered the country through boats and ships from neighboring countries.

This anthropophilic invasive Aedes mosquito was identified morphologically, which was confirmed by molecular assay for the first time in the country. Given that this species has been collected from two different locations in two periods of time in this study, this vector has been able to adapt to the new region's climatic conditions rapidly after entering the country. At the end of the hot season and at the beginning of the rainy season, Aedes aegypti mosquitoes began to grow and increase their population. The study results showed that scrap tires in disposal sites (both rural and urban areas) were ideal breeding places for Aedes aegypti adults to rest and lay their eggs. This has been reported in many other studies around the world [17-18].

Mitochondrial genes, especially the Culicidae family, are a good source for entomological studies [1923]. Mitochondrial genes exist in several versions, are easily reproducible, and can be read and studied 
more easily compared to the genes of nuclear chromosomes. Another advantage of mitochondrial genes is that they are directly inherited from the mother [24]. Furthermore, the study findings demonstrated that $\mathrm{COI}$ genes could be appropriately used for the detection of this invasive species. In general, the molecular identification of mosquito species has been proved to be very useful for identifying vector-borne diseases, particularly when it is hard to identify mosquitoes morphologically. This method is capable of identifying vector species throughout the life cycle from egg to adult and can even detect the pathogenic agents in these vectors.

In the recent years, there have been numerous reports of dengue fever from such countries as Pakistan, Sudan, Yemen, Saudi Arabia, India, Somalia, and Egypt. Some of these countries share a common border with Iran, and the risk of getting the disease is imminent. In most of these countries, Ae. aegypti is the main vector of dengue fever [25-29]. The detection of Ae. aegypti in Iran for the first time warns us that it may increase the risk of transmission of chikungunya, dengue, yellow fever, and Zika viruses from the endemic areas of the diseases in neighboring countries like Pakistan. In addition to significant health hazards, this phenomenon will have negative effects on the economy and ecotourism of the region. Therefore, it is crucial to extend and strengthen the surveillance of invasive Aedes mosquitoes and to consider the need for the rapid suppression of newly introduced Ae. aegypti populations in this tropical region of Iran. This dangerous species has the capacity to act as a potential vector for the transmission of a variety of arboviral diseases and, consequently, poses a real risk to public health and veterinary medicine. Hence, along with emphasis on vector control strategies, regular and more accurate inspections of seaports, particularly cargoes arriving from endemic countries of Ae. aegypti, are needed.

\section{Conclusions}

Aedes aegypti is an important vector for the transmission of arboviral diseases. The correct diagnosis of this vector represents one of the most important steps towards controlling vector-borne diseases. This study provided the first comprehensive detective report of this species in Iran (both molecular and morphological identification). Given the confirmation of the presence of this invasive vector in the studied area, the risk of local transmission is really high through the introduced cases of diseases from neighboring countries. Therefore, implementation of vector control programs with a precise and immediate surveillance system should be considered as the priority of the local health system in order to prevent the epidemic of arboviral diseases, such as dengue fever and chikungunya.

\section{Declarations}

\section{Acknowledgements}

Hereby, the authors would like to thank the Vice-chancellor for Research and Technology of Shiraz University of Medical Sciences. They would also like to express their gratitude to Dr. Ahmad Raesi and all health staff of Hormozgan University of Medical Sciences for their help and support. Thanks also go to 
Ms. A. Keivanshekouh at the Research Improvement Center of Shiraz University of Medical Sciences for improving the use of English in the manuscript.

\section{Authors' contributions}

KA, HD, and AS designed and performed the experiments, analyzed the data, and co-wrote the paper. KA, HD, AS, SAJH, MSN and HA performed the morphological and molecular identification of the specimens and co-wrote the paper. RS helped collect the samples and co-wrote the paper. KA and HA supervised the research.

\section{Funding}

This paper was partly derived from the M.Sc. thesis written by Mr. Hedayat Dorzaban (grant No. 1395-0104-13158) in Medical Entomology at School of Health, Shiraz University of Medical Sciences.

\section{Availability of data and materials}

All data generated or analyzed during this study are included in this published article.

\section{Ethics approval and consent to participate}

Not applicable.

\section{Consent for publication}

Not applicable.

\section{Competing interests}

The authors declare that they have no competing interests

\section{References}

1. Cook S, Diallo M, Sall AA, Cooper A, Holmes EC. Mitochondrial markers for molecular identification of Aedes mosquitoes (Diptera: Culicidae) involved in transmission of arboviral disease in West Africa. J Med Entomol 2005: 42: 19-28.

2. Keshavarzi D, Soltani Z, Ebrahimi M, Soltani A, Nutifafa GG, Soltani F, Faramarzi H, Amraee K, Hassanzadeh A.. Monthly prevalence and diversity of mosquitoes (Diptera: Culicidae) in Fars Province, Southern Iran. Asian Pacific J Trop 2017: D6-369

3. Kumar NP, Rajavel AR, Natarajan R, Jambulingam P. DNA barcodes can distinguish species of Indian mosquitoes (Diptera: Culicidae). J Med Entomol 2007: 44: 1-7.

4. Marrelli MT, Sallum MAM, Marinotti O.. The second internal transcribed spacer of nuclear ribosomal DNA as a tool for Latin American anopheline taxonomy: a critical review. Mem Inst Oswaldo Cruz 2006: 101: 817-832. 
5. Goswami G, Raghavendra K, Nanda N, Gakhar SK, Subbarao SK. PCR-RFLP of mitochondrial cytochrome oxidase subunit II and ITS2 of ribosomal DNA: markers for the identification of members of the Anopheles culicifacies complex (Diptera: Culicidae). Acta Trop 2005: 95: 92-99.

6. Beebe NW, Whelan PI, Van den Hurk AF, Ritchie SA, Corcoran S, Cooper RD. A polymerase chain reaction-based diagnostic to identify larvae and eggs of container mosquito species from the Australian region. J Med Entomol 2007: 44: 376-380.

7. Toma T, Miyagi I, Crabtree MB, Miller BR. Identification of Culex vishnui subgroup (Diptera: Culicidae) mosquitoes from the Ryukyu Archipelago, Japan: development of a species-diagnostic polymerase chain reaction assay based on sequence variation in ribosomal DNA spacers. $J$ Med Entomol 2000: 37: $554-558$.

8. Munstermann LE. Mosquito systema111tics: current status, new trends, associated complications. $J$ vector Ecol 1995: 20: 129-138.

9. Becker N, Petric D, Zgomba M, Boase C, Madon M, Dahl C, Kaiser A. Mosquitoes and their control. Springer Science \& Business Media. 2010.

10. Carpenter SJ, La Casse WJ. Mosquitoes of North America (North of Mexico). Univ of California Press. 1974.

11. Christophers SR.. Aedes aegypti: the yellow fever mosquito. CUP Archive. 1960.

12. Guzmán MG, Kouri G.. Dengue: an update. Lancet Infect Dis 2002: 2: 33-42.

13. Azari-Hamidian Sh. Checklist of Iranian mosquitoes (Diptera: Culicidae). Journal of Vector Ecology 2007: 32(2): 235-242.

14. Rueda LM.. Pictorial keys for the identification of mosquitoes (Diptera: Culicidae) associated with dengue virus transmission. Walter Reed Army Inst Of Research Washington Dc Department Of Entomology. 2004.

15. Soltani Z, Keshavarzi D, Ebrahimi M, Soltani A, Moemenbellah-Fard MJ, Soltani F, Faramarzi H, Amraee K, Elyasigomari A. The fauna and active season of mosquitoes in west of Fars province, southwest of Iran. Arch Razi Inst 2017. 72. https://doi.org/10.22092/ari.2017.111603

16. Dhananjeyan KJ, Paramasivan R, Tewari SC, Rajendran R, Thenmozhi V, Leo SV, Venkatesh A, Tyagi BK. Molecular identification of mosquito vectors using genomic DNA isolated from eggshells, larval and pupal exuvium. Trop Biomed 2010: 27: 47-53.

17. Chambers DM, Young LF, Hill JHS. Backyard mosquito larval habitat availability and use as influenced by census tract determined resident income levels. J Am Mosq Control Assoc 1986: 2: $539-544$.

18. Tinker ME.. Larval habitat of Aedes aegypti (L.) in the United States. Mosq News 1964: 24: 426-432.

19. Avise JC, Arnold J, Ball RM, Bermingham E, Lamb T, Neigel JE, Reeb CA, Saunders NC. Systematics,. Intraspecific phylogeography: the mitochondrial DNA bridge between population genetics and systematics. Ann. Rev Ecol 1987: 18: 489-522. 
20. Harrison RG. Evolution, Animal mitochondrial DNA as a genetic marker in population and evolutionary biology. Trends Ecol. 1989: 4: 6-11.

21. Hickey DA, Mitchell A, Sperling FAH, Evolution, Higher-level phylogeny of mosquitoes (Diptera: Culicidae): mtDNA data support a derived placement for Toxorhynchites. Insect Syst 2002: 33: 163174.

22. Liu H, Beckenbach AT.. Evolution of the mitochondrial cytochrome oxidase II gene among 10 orders of insects. Mol phylogenetics Evol 1992: 1: 41-52.

23. Simon C. Molecular systematics at the species boundary: exploiting conserved and variable regions of the mitochondrial genome of animals via direct sequencing from amplified DNA, in: Molecular Techniques in Taxonomy. Springer, pp. 1991: 33-71.

24. Krzywinski J, Besansky NJ.. Molecular systematics of Anopheles: from subgenera to subpopulations. Ann Rev Entomol 2003: 48: 111-139.

25. Ahmed S, Mohammad WW, Hamid F, Akhter A, Afzal RK, Mahmood A. The 2011 dengue haemorrhagic fever outbreak in Lahore-an account of clinical parameters and pattern of haemorrhagic complications. J Coll Physicians Surg Pak 2013: 23: 463-467.

26. Al-Shami SA, Mahyoub JA, Hatabbi M, Ahmad AH, Rawi CSM,. An update on the incidence of dengue gaining strength in Saudi Arabia and current control approaches for its vector mosquito. Parasit Vectors 2014: 7; 258.

27. Bharaj P, Chahar HS, Pandey A, Diddi K, Dar L, Guleria R, Kabra SK, Broor S. Concurrent infections by all four dengue virus serotypes during an outbreak of dengue in 2006 in Delhi, India Virol J 2008: 5, 1.

28. WHO. Summary report on the Intercountry meeting on the strategic framework for prevention and control of emerging and epidemic-prone diseases in the Eastern Mediterranean Region, Amman, Jordan 16-19 December 2018. World Health Organization. Regional Office for the Eastern Mediterranean. 2019.

29. Rezza G, El-Sawaf G, Faggioni G, Vescio F, Al Ameri R, De Santis R, Helaly G, Pomponi A, Metwally D, Fantini M. Co-circulation of dengue and chikungunya viruses, Al Hudaydah, Yemen, 2012. Emerg Infect Dis 2014: 20: 1351.

\section{Figures}




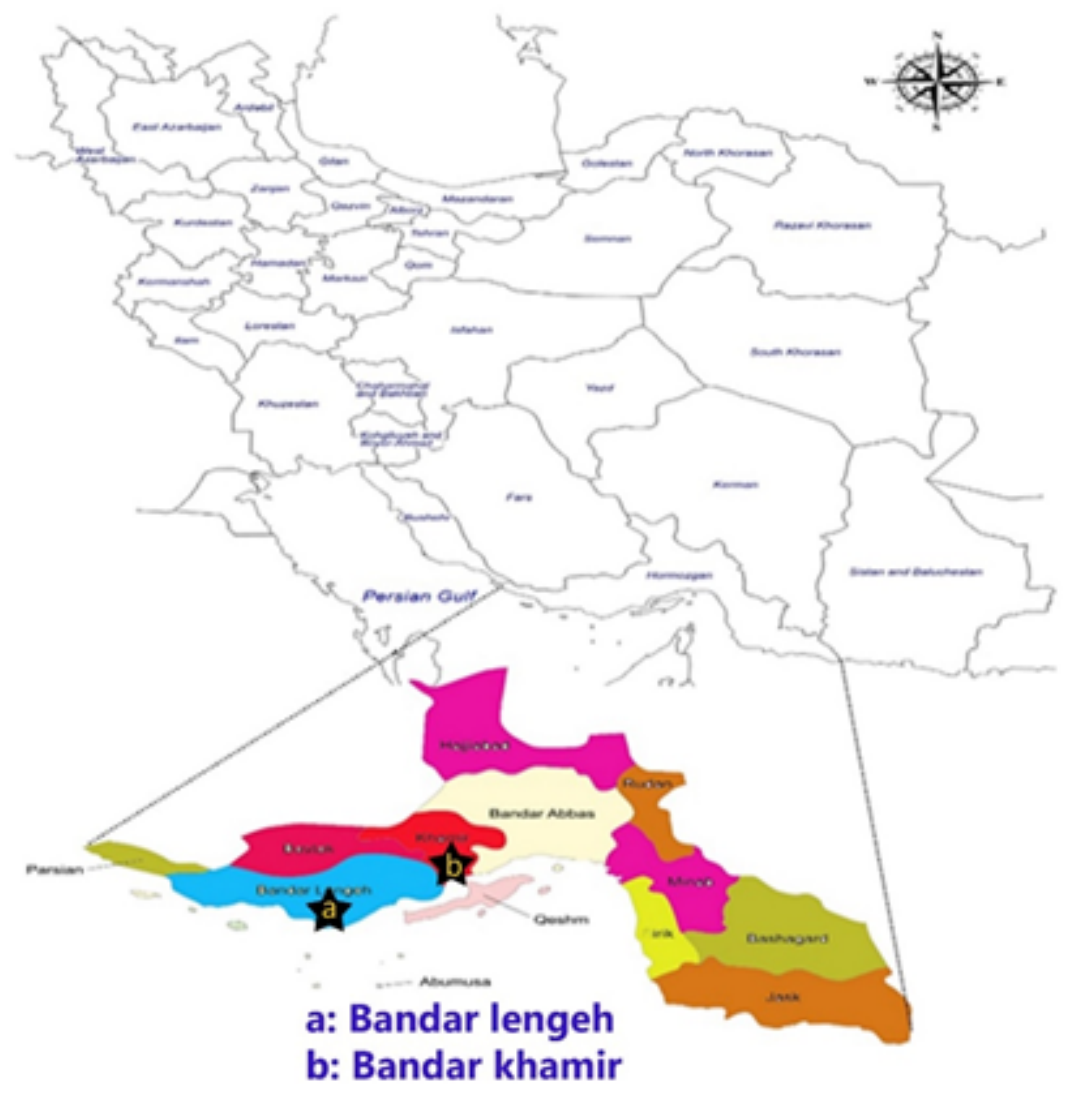

Figure 1

Map of Hormozgan province and its cities, south of Iran and the two points where Ae. aegypti were caught for the first time in the country

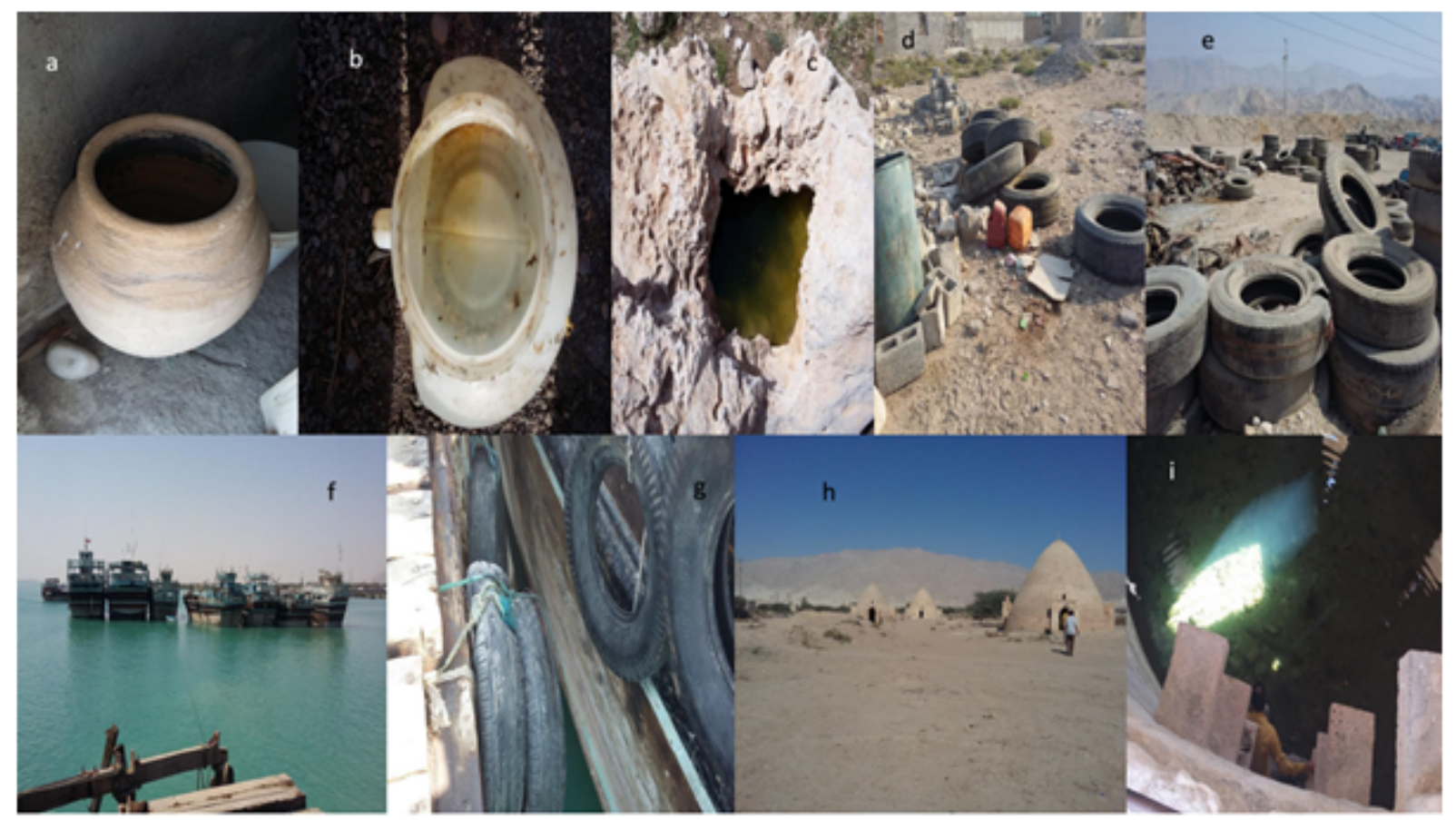




\section{Figure 2}

Various water reservoirs and sampling sites. a: a traditional water jug, b: a plastic water tank as a mosquito breeding place, c: a rainwater-filled hole, d: a rural scrap tire site, e: used tire disposal sites in an urban area, f: a small cargo ship, g: tires attached to a small ship, h: Abanbar (traditional water storages in arid areas of Iran), f: inside view of a water storage.

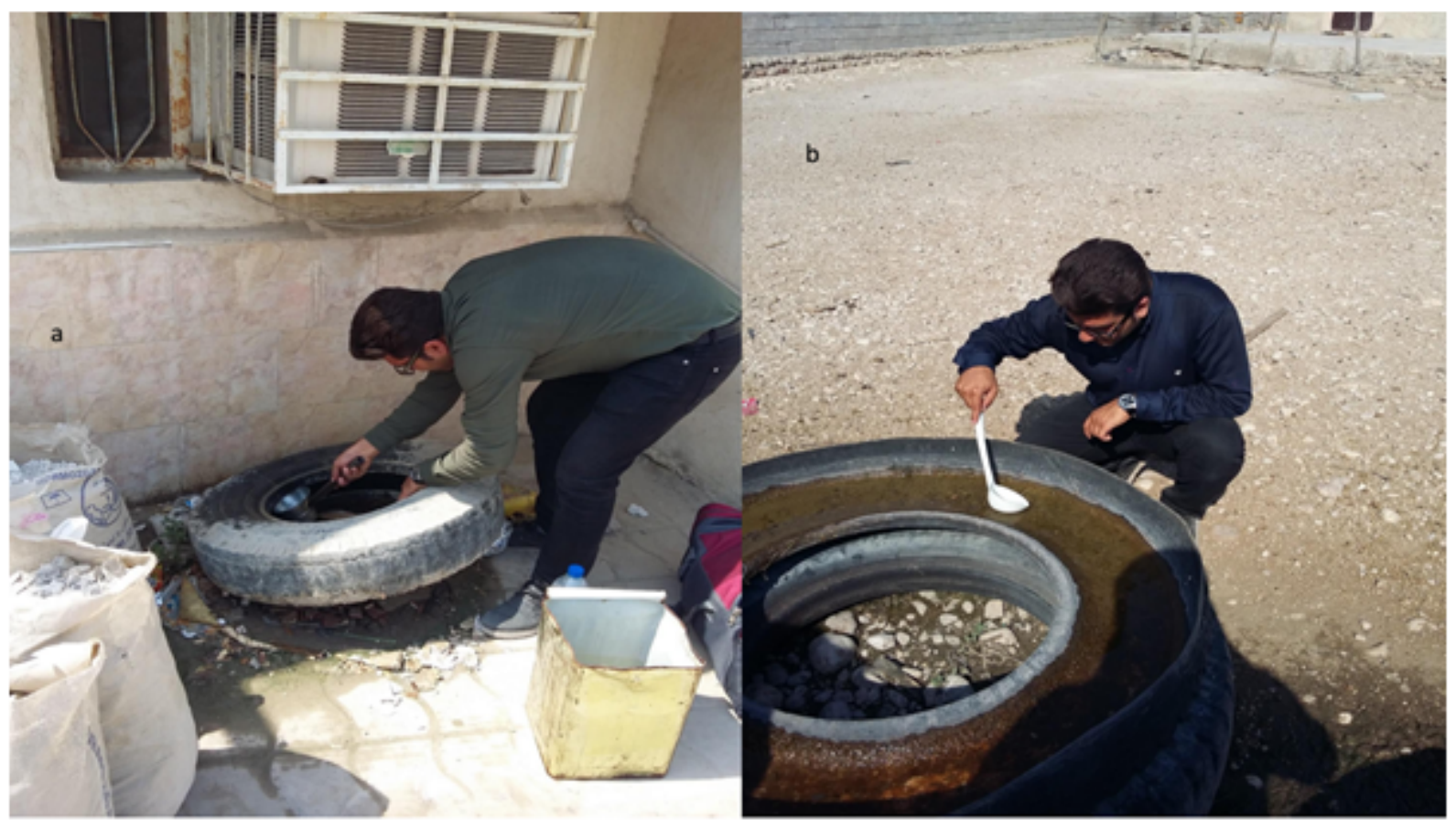

\section{Figure 3}

$\mathrm{a}$ and b: larval sampling from scrap tires as mosquito breeding places

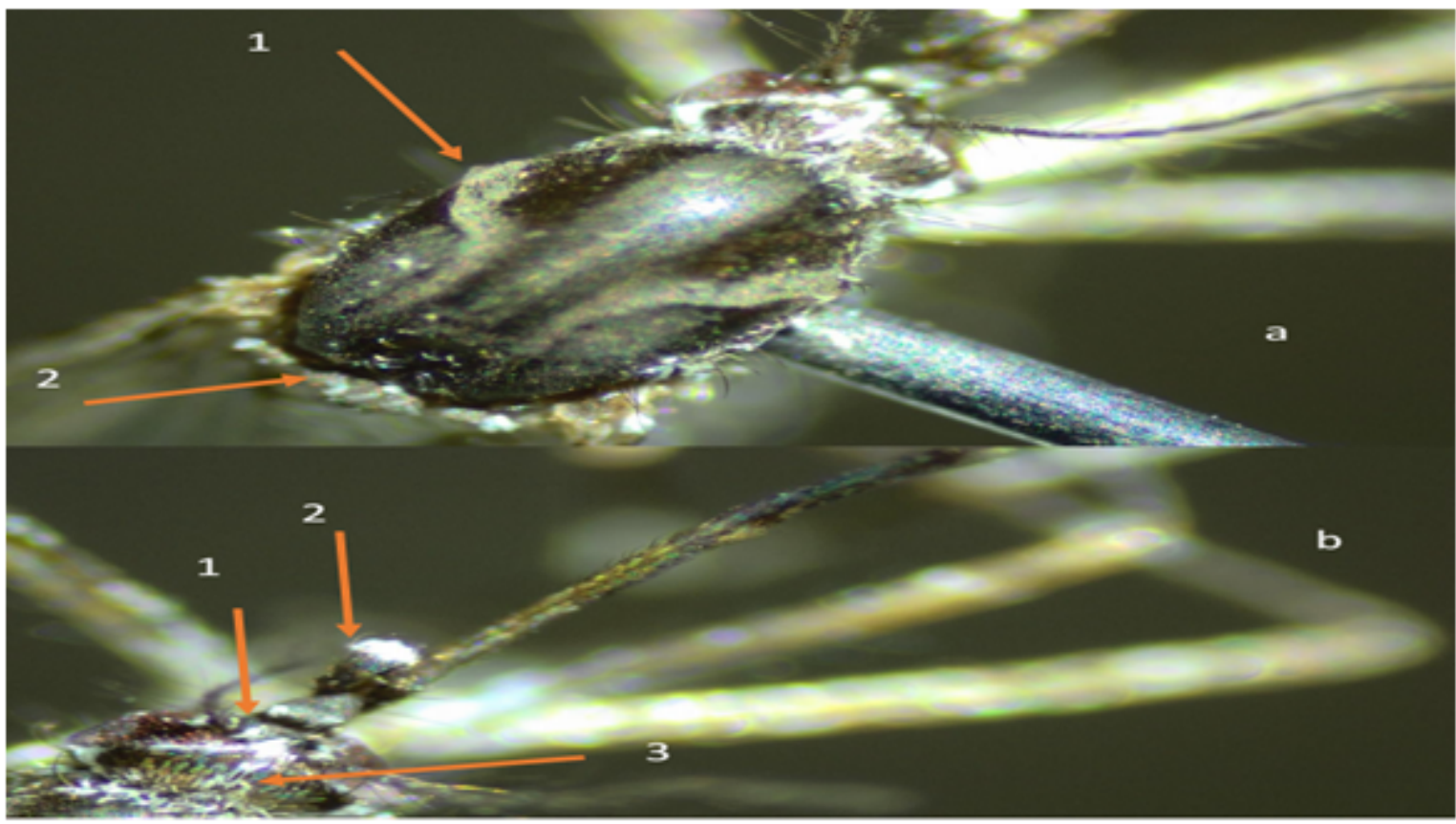




\section{Figure 4}

Dorsal view of Ae. Aegypti. a1: The scutum is predominantly covered with narrow dark brown scales, with a distinctive pattern of light scales (lyre shape). a2: The postpronotum has a patch of broad white scales and some dark and pale narrow scales on the upper part. b1: The clypeus with lateral white scales and the pedicel with large patches of white scales on the sides. b2: The palps $1 / 5$ of the length of the proboscis with white scales on the apical half. b3: Erect scales are restricted to the occiput and are all pale.

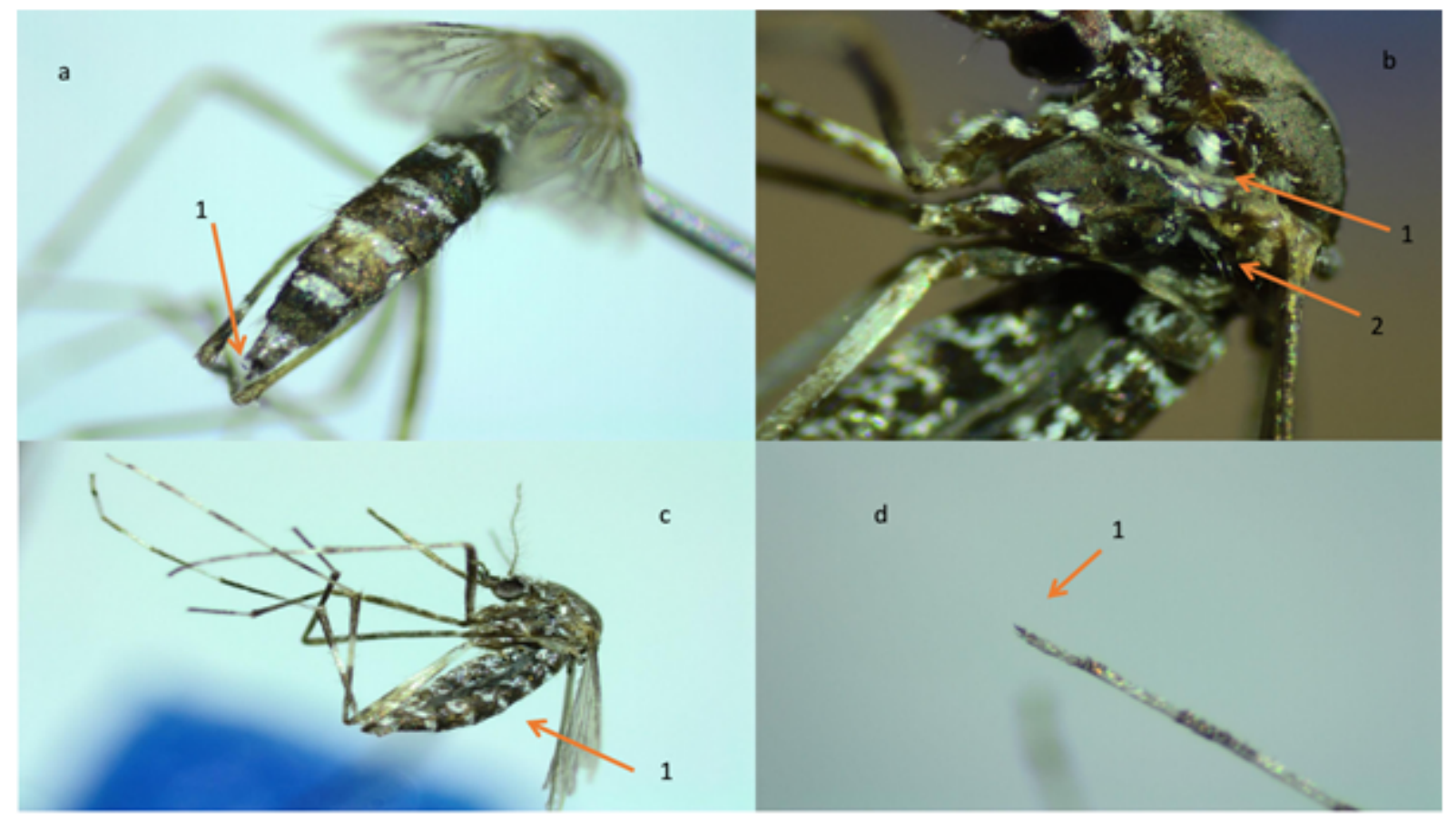

\section{Figure 5}

a1: The terminal part of the abdomen is needle-shaped. b1 and b2: The postspiracular area is without scales, but there are patches of broad white scales on the propleuron and subspiracular and hypostigmal areas. c1: All the tibiae are dark anteriorly, the fore and mid tarsi have a white basal band on tarsomeres I and II, the hind tarsus has a broad basal white band on tarsomeres I-IV, and tarsomere V is all white. d1: The claws of the fore and mid tarsi have a subbasal tooth, and the claws of the hind tarsi are simple. 


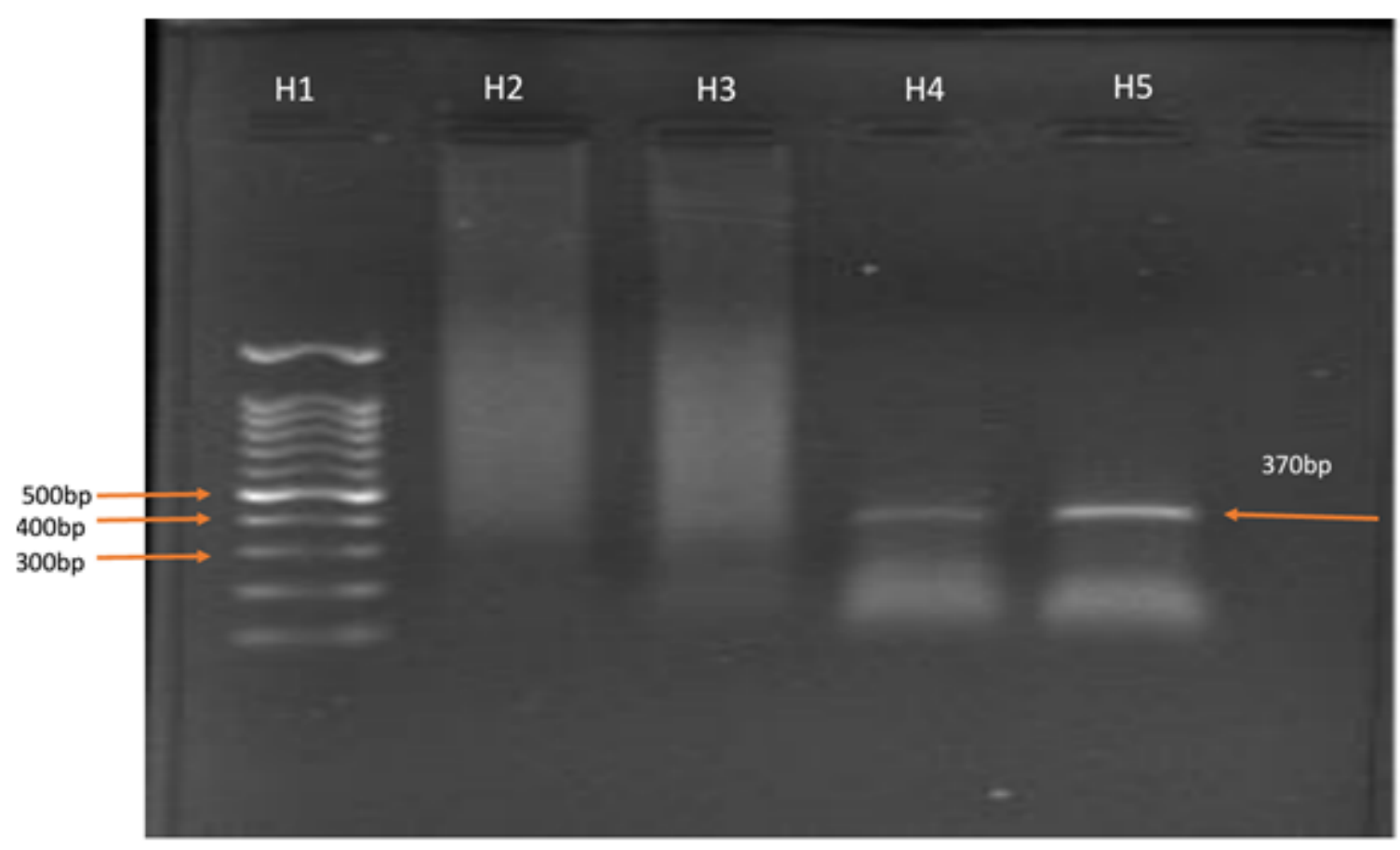

Figure 6

The electrophoresis image showing the amplification of the $\mathrm{CO} 1$ region of the collected Aedes aegypti mosquitoes. $0.1 \%$ agarose gel; $\mathrm{H} 1$ : ladder 100 bp (sina clon), H2: negative control, H3: DNA from adult Culex pipiens as the negative control, $\mathrm{H} 4$ : adult Aedes aegypti mosquitoes, $\mathrm{H} 5$ : larvae of Aedes aegypti mosquitoes.

\begin{tabular}{|c|c|c|c|c|c|c|}
\hline \multicolumn{2}{|c|}{$\begin{array}{l}\text { Score } \\
535 \text { bits(593) }\end{array}$} & $\begin{array}{l}\text { Expect } \\
6 \mathrm{e}-148\end{array}$ & $\begin{array}{l}\text { Identities } \\
298 / 299(99 \%)\end{array}$ & $\begin{array}{l}\text { Gaps } \\
0 / 299(0 \%)\end{array}$ & \multicolumn{2}{|c|}{$\begin{array}{l}\text { Strand } \\
\text { Plus/Plus }\end{array}$} \\
\hline Query & 1 & & & 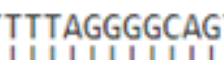 & TTTATT & 60 \\
\hline Sbjet & 187 & GCTATTTTTTCTCT & GAAI & TTAGGGGCAG & TTTATT & 246 \\
\hline Query & 61 & & CGATCGTS & GATCGA $>$ \& $\Rightarrow$ & & 120 \\
\hline Sbjet & 247 & ACAACTGTAATTAA & ACGATCGTCAGGAA & AGATCGACTAC & ITTGTT & 306 \\
\hline Query & 121 & TGATCTGTAGTT & & & GAGCT & 180 \\
\hline Sbjet & 307 & ${ }^{\circ}$ & . & Not +8 & AGCT & 366 \\
\hline Query & 181 & TATATTATT & ACCGAAACTTA & TCITTGAT & GGAGGA & 240 \\
\hline Sbjet & 367 & AITACTAIUITAIT & 年 & IVITIGAI & GGAGGA & 426 \\
\hline Query & 241 & & & $\operatorname{CCACACCCA~}$ & ATAT & 299 \\
\hline Sbjet & 427 & GGAGATCCTATTTT & CCAACACTTATTCT & TGGACACCCAG & ГTATAT & 485 \\
\hline
\end{tabular}

Figure 7 
The result of alignment sequencing (COI gene) of the captured Aedes aegypti in south and southwest of Iran by NCBI

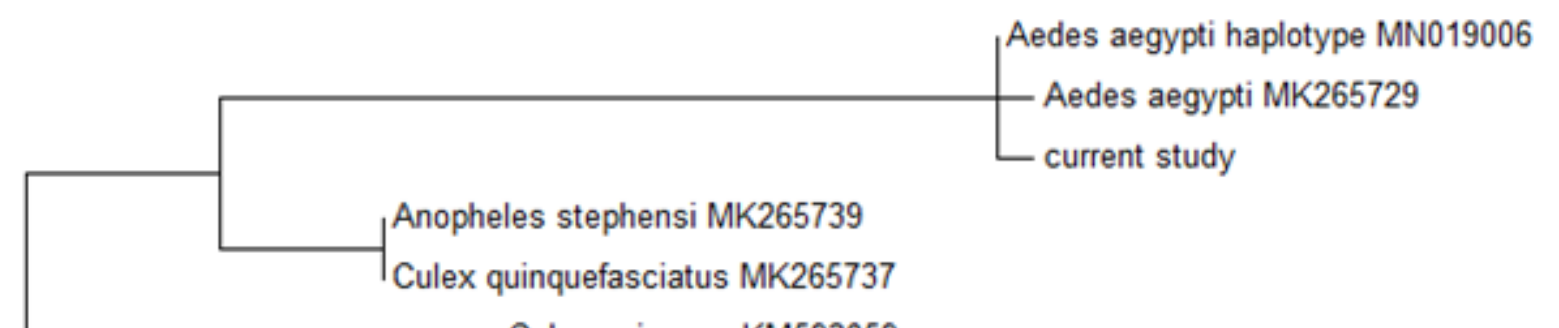

Haemagogus lucifer KM593036

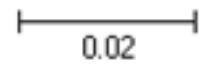

Figure 8

Phylogenetic tree (COI gene) of the captured Aedes aegypti. The $\mathrm{COI}$ nucleotides were aligned using MEGA 6.0 software based on the ClustalW method by using the sequences characterized from Aedes, Anopheles, and Culex. The phylogenetic tree revealed that the current sequence was highly similar to Ae. eagypti.

\section{Supplementary Files}

This is a list of supplementary files associated with this preprint. Click to download.

- GraphicalAbstract.png 